Vesna Colic*

doi: 10.19090/zop.2017.26.137-155

Tamara Milošević

UDC: $159.93-053.4$

Uglješa Colić

Originalni naučni rad

Visoka škola strukovnih studija za

obrazovanje vaspitača, Novi Sad

\title{
OPAŽANJE, SHVATANJE I PREDSTAVLJANJE PROSTORA KOD DECE PREDŠKOLSKOG UZRASTA
}

Apstrakt: Orijentacija dece u prostoru je značajna za celokupan razvoj, kao i razvoj specifičnih veština koje su važne, kako za snalaženje u svakodnevnom životu, tako i za uspeh u nekim školskim predmetima (naročito za čitanje, pisanje, računanje, likovno i fizičko vaspitanje). Dolazak dece u vrtić, kao svakodnevna životna situacija, može da obezbedi dragocena iskustva za razvoj orijentacije u prostoru. Cilj istraživanja je da se utvrdi kako deca opažaju, shvataju i grafički predstavljaju prostor kroz koji se svakodnevno kreću. Uzorak istraživanja čini 156 ispitanika (dece), po 52 od 4,5 i 6 godina, uz podjednaku zastupljenost devojčica i dečaka. Sva deca pohađaju neki od vrtića u Novom Sadu. Korišćena je metoda intervjua i crtanja mape puta od kuće do vrtića. Rezultati istraživanja - dobijeni analizom odgovora na pitanja i analizom crteža dece - pokazali su da deca iz uzorka relativno dobro opažaju, razumeju i predstavljaju prostor, ali ova situacija nije u dovoljnoj meri iskorišćena za unapređivanje dečjeg razumevanja pravca kretanja i korišćenja simbola u predstavljanju prostora. Odrasli bi trebalo da poklanjaju veću pažnju dečjem neposrednom iskustvu, više razgovaraju sa decom o njihovim doživljajima prostora i prostornih odnosa, kao i da podstiču decu da češće crtaju mape i više se služe različitim simbolima.

Ključne reči: deca, prostor, opažanje, shvatanje, predstavljanje.

\section{UVOD}

Pojam prostora sreće se u različitim naukama (filozofiji, matematici, fizici), ali i umetnosti (likovnoj umetnosti, arhitekturi) i u svakodnevnom životu. Proučavanja etnografske i istorijske građe dovodi do zaključka da se prostor u različitim kulturama i različitim vremenima različito doživljavao, tumačio, organizovao i koristio. Posebno pitanje je kako se kod dece

\footnotetext{
*Vesna Colić, colic.vesna@gmail.com
} 
razvijaju pojmovi o prostoru, koji su za njih od velike važnosti, kako za snalaženje u svakodnevnom životu, tako i za uspeh u nekim školskim predmetima (naročito za čitanje, pisanje, računanje, likovno i fizičko vaspitanje). Dečije viđenje prostora se, nesumnjivo, razlikuje od viđenja odraslih, te ga je tim teže istraživati i razumeti.

Teorijski okvir za istraživanje orjentacije dece u prostoru u ovom radu čine teorije razvoja deteta Pijažea i Vigotskog, kao i novija istraživanja o značaju i razvoju prostornog ponašanja i orijentisanja uopšte. Ta istraživanja ukazuju da je prostorni razvoj važan za evoluciju, adaptaciju i svakodnevno funcionisanje čoveka. Prostorne sposobnosti se takođe smatraju ključnom komponentom ljudskog intelekta, pa je tako i prostorna inteligencija jedan od tipova inteligencije predloženih u Gardnerovoj teorije višestruke inteligencije (Newcombe, Uttal \& Sauter, 2013).

Smatra se da je razvoj opažanja i shvatanja prostora uslovljen, kao uostalom i razvoj deteta u celini, jednim delom sazrevanjem, ali i bogatstvom i karakterom neposrednog iskustva deteta u vezi sa prostornim pojavama. Dete koje ima bogato neposredno iskustvo i brojne prilike da interiorizuje i transformiše to iskustvo u interakciji sa odraslima i drugom decom, uspešno će ovladati prostorom, što će doprineti njegovom uspešnom snalaženju u prirodnoj i društvenoj sredini. Ukoliko su njegova iskustva siromašna, kao i prilike za preradu tog iskustva, dete će imati poteškoća u raznim poljima delatnosti, otežan opšti razvoj i neke specifične teškoće, među kojima se navode i teškoće u početnom čitanju i pisanju. Zbog toga autori rada smatraju da je veoma važno koristiti svaku životnu situaciju u kojoj deca i odrasli zajedno učestvuju za bogaćenje dečjeg iskustva, doživljaja prostora i prostornih odnosa i simboličke reprezentacije. Posebnu vrednost će imati one situacije koje su za dete važne, među kojima je sigurno i dolazak u vrtić, situacija koja je neposredni predmet interesovanja u ovom radu.

\section{TEORIJSKE OSNOVE ISTRAŽIVANJA}

Jedno od polazišta u ovom radu bila je Pijažeova teorija i njegova shvatanja o razvoju inteligencije i opažanja dece predškolskog uzrasta. Prema njegovom mišljenju, saznajni razvoj nije rezultat samo sazrevanja, niti samo 
uticaja sredine, već se odvija u interakciji sazrevanja i sredine. Saznanje nije kopija realnosti, već je ,proces dinamične interakcije“ između misli i stvarnosti (Tarner, 1979:10). Ono nastaje na osnovu delovanja deteta na sredinu kojim modifikuje i transformiše objekte, gradi sve složenije kognitivne sheme i aktivno konstruiše svoje znanje. U okviru njegove teorije, ipak nije nađeno potpuno objašnjenje za predmet ovog istaživanja, jer se smatralo da za njegovo razumevanje nije dovoljno osloniti se samo na individualno razmišljanje deteta o sopstvenoj aktivnosti. Otuda je važan izvor sociokulturna teorija Vigotskog, koji u većoj meri naglašava uticaj drugih ljudi u procesu mišljenja i saznavanja.

Mnogi savremeni istraživači ističu ulogu socijalnog konteksta i interakcije sa drugim ljudima u kognitivnom razvoju. Vigotski smatra da posebno važnu ulogu u dečjem razvoju i učenju ima interakcija između odraslog i deteta. Ukoliko se te interakcije odvijaju tokom upoznavanja i doživljavanja svakodnevih događaja deteta u neposrednom okruženju, tada u najvećoj meri doprinose razvoju i učenju (Medouz i Kešdan, 2000). Na taj način je Vigotski posebno naglasio važnost socijalnog konteksta i podrške koju pruža celokupnom razvoju.

Zbog izuzetnog značaja koje imaju prostorne sposobnosti, kao neophodna komponenta i veština inteligencije uopšte, ali i kao preduslov uspešnog bavljena različitim naučnim, tehnološkim, inženjerskim i matematičkim disciplinama, sve veća pažnja istraživača usmerena je na istraživanja razvoja prostorne simboličke reprezentacije (Newcombe et al. 2013). Njihova istraživanja pokazala su da se simboličke reprezentacije razvijaju zahvaljujući količini informacija koje se direktno, a u još većoj meri indirektno, dobijaju. Takođe, ističe se i kvalitet informacija, pri čemu se mape, kao prenosioci informacija, smatraju značajnijim od jezika jer prenose više elemenata i ukazuju na neke pojedinosti koje su važne za rešavanje zadataka. Korišćenje jezika je najčešće i smatra se da on ima značajnu ulogu u poboljšanju kvaliteta informacija. Pored jezika i mapa, prostorni simbolički sistem čine i gestovi, koji su slični slikama, ali za razliku od njih mogu da uključe samo dva elementa informacije istovremeno (Newcombe et al. 2013).

Kada se pokušalo definisati šta je prostor, pošlo se od činjenice da ga dete saznaje kroz niz aktivnosti vezanih za određeno mesto, te gradi svoje 
razumevanje prostora stičući lično iskustvo. Svakako da i osobine samog prostora utiču na detetov doživljaj. Prema poznatom američkom arhitekti Linču (Lynch, 1974), sadržaj slike prostora može se objasniti kroz pet elemenata: putevi, granice, distrikti (područja), čvorišta i orijentiri (obeležja). To su dominantni elementi u prostoru koji služe kao orijentiri, pri čemu nijedan od tipskih elemenata ne postoji kao izdvojena jedinica - oni se preklapaju i uzajamno prožimaju.

Kada se govori o percepciji i deci, treba imati na umu da svet iz perspektive deteta ne izgleda isto kao iz perspektive odraslog. Razlike se javljaju već u vezi sa dimenzijama. Detetu jedan prostor može izgledati ogroman, dok odraslima ne daje takav doživljaj. Svet kakvog ga mi poznajemo za dete izranja tek posle godina iskustva, a sve potpomognuto promenama koje se dešavaju u sazrevanju njegovog centralnog nervnog sistema tokom najranijeg detinjstva, kao i neposrednom interakcijom sa fizičkim i socijalnim okruženjem (Jerković i Zotović, 2010).

Istraživanja pokazuju da deca od 4-5 godina najčešće dobro opažaju i pravilno imenuju prostorne odnose (iza, pored, iznad, ispod), kao i pravac kretanja u prostoru (levo, desno, napred, nazad) (Djačenko i Lavrentjev, 1988). Međutim, kada se nađe u novoj, nepoznatoj, situaciji velika je verovatnoća da će dete imati poteškoća da se orijentiše. Jedna od tih situacija može biti polazak u školu, kada će mu ove poteškoće otežati savladavanje čitanja i pisanja. Klemenović (2014) ističe da je zato veoma važno da se pored poznatog direktnog pripremanja deteta za polazak u školu i svaku novu situaciju, koriste i posredni načini, kao što su razgovor, igra, čitanje detetu, izleti, posete i putovanja i uopšte bogaćenje njegovog iskustva. Otuda se u literaturi preporučuje da vaspitači predškolske dece kreiraju različite situacije i prilike za učenje dece o prostoru i prostornim odnosima, da ih podstiču da identifikuju objekte, da koriste reči koje označavaju prostorne odnose, da opisuje veze i pozicije između objekata i slično (Dauksas \& White, 2014).

$\mathrm{U}$ jednom od istraživanja Harvardskog istraživačkog centra posvećenog porodici (Harvard Family Research Project), koji se bavio procesom prelaska deteta iz vrtića u školu, utvrđeno je, između ostalog, da zavisi od nekoliko faktora. Za ovaj rad je važan podatak da dobra orijentacija $\mathrm{u}$ prostoru umnogome može pomoći detetu da se bolje snađe u novoj 
situaciji. Poznavanje objekta škole i sličnost sa objektom vrtića - koji mu je već poznat - doprineće da taj proces bude manje stresan, ali će takođe povoljno uticati na razvoj socijalnih, emocionalnih i akademskih veština (Caspe, Lopez \& Chattrabhuti, 2015).

\section{METOD}

Predmet istraživanja je opažanje i shvatanje prostora dece predškolskog uzrasta.

Cilj istraživanja je da se utvrdi kako deca predškolskog uzrasta opažaju i shvataju prostor kroz koji se svakodnevno kreću i kako ga grafički predstavljaju. Ovim radom želi se ukazati na značaj jedne svakodnevne životne situacije, tj. dolazak deteta u vrtić, za razvoj detetovog opažanja i shvatanja prostora. Takođe, želi se proceniti da li se u praksi ova situacija dovoljno koristi za razvoj opažanja i shvatanja prostornih odnosa kod predškolske dece i posebno da ukaže na potrebu korišćenja svih životnih situacija i aktivnosti za razvoj shvatanja prostornih odnosa.

Uzorak istraživanja je 156 ispitanika - predškolske dece, po 52 od 4, 5 i 6 godina, uz podjednaku zastupljenost devojčica i dečaka u okviru svih obuhvaćenih uzrasta. Sva deca pohađaju neki od vrtića u gradu Novom Sadu. Uzorak je prigodan, nije reprezentativan, te su mogućnosti uopštavanja rezultata ograničene, ali se veruje da ukazuju na neke najopštije tendencije $u$ vezi sa predmetom istraživanja.

U istraživanju je primenjen intervju sa decom i analiza dečjih crteža. Razgovor sa decom su vodili njihovi vaspitači ili studenti Visoke škole strukovnih studija za obrazovanje vaspitača (Novi Sad) na praksi u prisustvu vaspitača, što znači deci poznate osobe. Razgovori su vođeni u prostorijama vrtića, odnosno u deci poznatom prostoru, tako da su bila potpuno sigurna i opuštena tokom intervjua. Postavljena su im sledeća pitanja:

1. Sa kime dolaziš u vrtić?

2. Kako dolaziš u vrtić?

3. Opiši kuda sve prolaziš. Šta i koga vidiš?

4. Kako znaš da si stigao/stigla? 
Nakon obavljenog razgovora, deca su crtala mapu svog puta od kuće do vrtića i crteži su prilagani uz zapis o svakom pojedinom razgovoru. Odgovori na pitanja razvrstani su po kategorijama i statistički obrađeni. Analiza crteža je rađena uzimajući u obzir likovne elemente i u poređenju sa usmenim odgovorima dece. Uzeti su u obzir različiti aspekti: uzrast i pol deteta, šta je dete nacrtalo, kako, kao i kako je to povezano sa verbalnim iskazom.

\section{ANALIZA I INTERPRETACIJA REZULTATA}

Tabelama koje slede prikazani su odgovori na četiri pitanja koja su postavljena deci; podvrgnuti su deskriptivnoj statistici. U posebnom odeljku prikazana je analiza dečjih crteža.

Tabela 1. Odgovori na pitanje 1. Sa kim dolaziš u vrtić?

\begin{tabular}{lcccccc}
\hline \multicolumn{1}{c}{ Kategorije: } & & $\begin{array}{c}\text { Jedna } \\
\text { osoba }\end{array}$ & $\begin{array}{c}\text { Dve } \\
\text { osobe }\end{array}$ & $\begin{array}{c}\text { Tri i više } \\
\text { osobe }\end{array}$ & $\begin{array}{c}\text { Nešto } \\
\text { drugo }\end{array}$ & Ukupno \\
\hline Pol & Uzrast & & & & & \\
Devojčice & 4 & 9 & 11 & 6 & 0 & 26 \\
& 5 & 11 & 12 & 2 & 1 & 26 \\
& 6 & 10 & 12 & 4 & 0 & 26 \\
\hline Dečaci & 4 & 11 & 10 & 4 & 1 & 26 \\
& 5 & 8 & 16 & 1 & 1 & 26 \\
& 6 & 7 & 11 & 7 & 1 & 26 \\
\hline Ukupno & 4 & 20 & 21 & 10 & 1 & 52 \\
& 5 & 19 & 28 & 3 & 2 & 52 \\
& 6 & 17 & 23 & 11 & 1 & 52 \\
& & & & & & \\
& Svi & 56 & 72 & 24 & 4 & 156 \\
\hline
\end{tabular}

Iz Tabele broj 1, gde su prikazani odgovori na pitanje „Sa kim dolaziš u vrtić?“", primetno je da najveći broj dece (72 dece, odnosno 46,15\%) dolazi u vrtić sa dve osobe. Može se videti da su to najčešće roditelji deteta, mama i tata, kada su oni često navodili „mama me dovodi, a tata dolazi po mene“, ili obrnuto. Bilo je slučajeva gde su deca davala odgovore da dolaze sa mamom 
ili tatom, u zavisnosti od drugih faktora, kao na primer, „kad se mama uspava“, „uvek dolazim sa dedom, ali je sada povredio nogu, pa me tata dovozi“, ,jedan dan sa mamom, jedan dan sa tatom“ i slično. Druge osobe koje se javljaju u odgovorima dece su bake i deke. Nešto manji broje dece (56, odnosno $35,9 \%$ ) dalo je odgovor da u vrtić dolaze sa jednom osobom. To su uglavnom roditelji, mama ili tata, ali najčešći odgovor je bio „sa mamom uvek“. Ovi podaci mogu se dovesti u vezu sa opažanjem sredine od strane deteta. Veruje se da, kada decu dovode u vrtić iste osobe, dolaze istim ili sličnim putem, na isti ili sličan način, dsklr, ona imaju prilike da dobro upoznaju svoj put od kuće do vrtića. Potvrda za to može se naći u dečjim odgovorima na naredna pitanja (opis puta i po čemu znaju da su stigli), koji su kod većine ove dece bili slikoviti, jasni i sigurni. Što se tiče pola i uzrasta, nije primećena neka značajnija razlika u odgovorima kod ovog pitanja.

Sa tri i više osoba dolazi 24 dece, tačnije 15,38 \%. Tu su uglavnom, pored roditelja, druga deca (braća, sestre, druga deca koja idu u školu ili u vrtić). Ovde je primećena razlika $u$ odnosu na uzrast deteta, 10 četvorogodišnjaka i 11 šestogodišnjaka ide sa više osoba, dok je samo 3 petogodišnjaka navelo ovaj odgovor. $U$ odnosu na pol dece, kod četvorogodišnjaka je više devojčica, a od šestogodišnjaka češće dečaci idu u vrtić sa tri i više osobe. Primećeno je da su ova deca na drugo pitanje davala opširnije odgovore jer su opisivala i različite načine na koje dolaze u vrtić sa različitim osobama.

U kategoriju „,nešto drugo“ svrstani su odgovori četvoro dece, odnosno 2,56\%. Dva dečaka su odgovorila „dolazim sam“, jedan „koga nađem da me doveze, sa njim dođem“ i jedna devojčica je navela da dolazi „sa decom“. Iz njenih kasnijih odgovora može se videti da stanuje preko puta vrtića.

Na pitanje „Kako dolaziš u vrtić“،, 46,79\% dece, tačnije njih 73, navelo je da dolazi sopstvenim prevozom, autom ili biciklom. Najčešći odgovor je glasio ,autom“, a dolazak biciklom su često povezivali sa lepim vremenom (,kad je lepo vreme, dolazimo biciklom“). U pogledu uzrasta dece, može se primetiti da najviše četvorogodišnjaka (32, ujednačeni polom) dolazi sopstvenim prevozom, dok su kod starije dece prisutni raznovrsniji 
odgovori. To se može povezati sa činjenicom da se mlađa deca sporije kreću a odrasli najčešće žure, te su primorani da koriste neki vid prevoza.

Tabela 2. Odgovori na pitanje 2. Kako dolaziš u vrtić?

\begin{tabular}{lccccccc}
\hline Kategorije: & & Peške & $\begin{array}{l}\text { Sopstvenim } \\
\text { prevozom }\end{array}$ & $\begin{array}{l}\text { Javni } \\
\text { prevoz }\end{array}$ & $\begin{array}{l}\text { Kombinacija } \\
\text { prethodnih } \\
\text { kategorija }\end{array}$ & $\begin{array}{l}\text { Nešto } \\
\text { drugo }\end{array}$ & Ukupno \\
\hline Pol & Uzrast & & & & & & \\
Devojčice & 4 & 2 & 16 & 0 & 6 & 2 & 26 \\
& 5 & 4 & 12 & 0 & 10 & 0 & 26 \\
& 6 & 0 & 11 & 0 & 14 & 1 & 26 \\
\hline Dečaci & 4 & 2 & 16 & 1 & 7 & 0 & 26 \\
& 5 & 7 & 6 & 3 & 10 & 0 & 26 \\
& 6 & 4 & 12 & 1 & 9 & 0 & 26 \\
\hline Ukupno & 4 & 4 & 32 & 1 & 13 & 2 & 52 \\
& 5 & 11 & 18 & 3 & 20 & 0 & 52 \\
& 6 & 4 & 23 & 1 & 23 & 1 & 52 \\
& Svi & 19 & 73 & 5 & 56 & 3 & 156 \\
\hline
\end{tabular}

U daljoj analizi najfrekventniji odgovori dobijeni su u kategoriji „kombinacija auto/bicikl/peške“ (56 - 35,9\%). Ovo je očekivan rezultat s obzirom na to da veći broj dece $(51,28 \%)$ dolaze sa više osoba u vrtić, pa samim tim i na više različitih načina. To su i sama deca navodila: „kad dolazim sa mamom, idemo peške, kad dolazim sa dedom, idemo biciklom“, „sa tatom i to autom“ i sl. Ponekad su ove kombinacije povezane i sa vremenskim uslovima. Smatra se da to može značajno uticati na orijentaciju deteta u prostoru jer je poznato da je ponavljanje draži jedan od značajnih faktora usmeravanja pažnje, od čega zavisi naša percepcija (Jerković i Zotović, 2010). Jedna devojčica je ispričala: „Mamu je jednom zaustavila policija, i ja sam tada lepo videla kuda idemo, jer je mama tada vozila polako." Iz odgovora se upravo vidi da način, osobe, te učestalost na koju deca naviknu u velikoj meri utiču na njihov doživljaj okoline, a samim tim i snalaženje u njoj.

Od ukupno 156 dece obuhvaćenih uzorkom, 12,18\% (njih 19) dolazi peške u vrtić $i$ to najviše petogodišnjaka. Analizom njihovih odgovora na 
naredna pitanja uočeno je da su ta deca najčešće ukazivala na pravac kretanja u opisu kuda prolaze (,ideš pravo, pa skreneš levo, pa desno“ i sl). Takođe, ova deca su detaljnije opisivala pored čega prolaze (,,pored škole koja je žute boje“, „pored prodavnice sa puno slatkiša“, „,vidim rupe“ itd). Ista deca su na pitanje Kako znaš da si stigao? dali preciznije odgovore („vidim vrtić“, „vidim ogradu od vrtića“, „vidim znak bubamaru i znam da je to moj vrtić“ i slično), što pokazuje da su bolje opažali svoju okolinu. Realno je pretpostaviti da su usput, dok su dolazili peške, razgovarali sa odraslima o stvarima koje vide, što je tokom vožnje automobilom sigurno teže.

Da dolaze javnim prevozom, autobusom ili taksijem navelo je petoro dece, preciznije - $(3,21 \%)$ svi dečaci. Opisi ove dece o tome kuda sve prolaze su vrlo jednostavni, pretpostavlja se da je razlog tome nemogućnost da iz autobusa vide okolinu. Što se tiče poslednje kategorije (,nešto drugo“), tu su neodređeni odgovori 3 devojčice $(1,92 \%)$.

Ukoliko se pođe od Pijažeovog shvatanja da organizam usavršava svoje saznajne strukture usled dodira sa okolinom (Pijaže i Inhelder, 1996), smatra se da način kako dete dolazi od kuće do vrtića u velikoj meri utiče na njegovo saznanje o prostoru. Pošto veliki broj dece iz uzorka (46,79\%) dolazi nekom vrstom prevoza, ličnim ili javnim, može se pretpostaviti da to u velikoj meri ograničava njihov aktivni odnos sa okolinom i neposredno čulno iskustvo, pa samim tim i opažanje i razumevanje svoje okoline.

Iz odgovora na treće pitanje vidi se da su deca najčešće opisivala građevine / fizičke objekte pored kojih prolaze (116 odgovora, što iznosi $36,36 \%$ svih dobijenih odgovora). To su najčešće: kuće, zgrade, prodavnice, trafike, pekare, pijaca. Kao orijentir pojavila se i škola kod dece od 5 i 6 godina, što se može povezati sa njihovim skorim polaskom u školu, a takođe i benzinska pumpa, u odgovoru deteta koje tata dovozi u vrtić kolima. Neka deca iz uzorka nabrajaju i ograde pored kojih prolaze, što je povezano sa fizičkim rastom, odnosno veličinom deteta. Kako su deca niža rastom nego odrasli, bolje opažaju objekte koji su u visini njihovih očiju. Relativno često su dobijani odgovori povezani sa saobraćajem i saobraćajnicama, na primer: put, tunel, most, železnička stanica, semafor, pešački prelaz, parking, koji se i inače smatraju strateškim tačkama u strukturi gradova i važnim orijentirima za snalaženje (Lynch, 1974). Odgovori o građevinama i saobraćajnicama bili 
su najčešći kod dece sva tri uzrasta obuhvaćena istraživanjem. Što se tiče pola dece, devojčice su za nijansu češće navodile građevine, dok dečaci malo češće navode orijentire u vezi sa saobraćajem.

Tabela 3. Odgovori na pitanje 3. Opiši kuda sve prolaziš. Šta i koga vidiš?

\begin{tabular}{|c|c|c|c|c|c|c|c|c|}
\hline \multicolumn{2}{|l|}{ Kategorije: } & \multirow{2}{*}{$\begin{array}{l}\text { Osobe } \\
\text { koje } \\
\text { sreće }\end{array}$} & \multirow[t]{2}{*}{ Građevine } & \multirow[t]{2}{*}{$\begin{array}{l}\text { Zelene } \\
\text { površine }\end{array}$} & \multirow[t]{2}{*}{ Saobraćajnice } & \multirow[t]{2}{*}{$\begin{array}{l}\text { Pravac } \\
\text { kretanja }\end{array}$} & \multirow[t]{2}{*}{$\begin{array}{l}\text { Nešto } \\
\text { drugo }\end{array}$} & \multirow[t]{2}{*}{ Ukupno } \\
\hline Pol & Uzrast & & & & & & & \\
\hline \multirow[t]{3}{*}{ Devojčice } & 4 & 5 & 16 & 8 & 9 & 3 & 3 & 44 \\
\hline & 5 & 2 & 22 & 9 & 11 & 3 & 5 & 52 \\
\hline & 6 & 6 & 24 & 10 & 12 & 3 & 4 & 59 \\
\hline \multirow[t]{3}{*}{ Dečaci } & 4 & 3 & 18 & 9 & 12 & 1 & 6 & 49 \\
\hline & 5 & 5 & 19 & 9 & 16 & 6 & 1 & 56 \\
\hline & 6 & 12 & 17 & 7 & 13 & 5 & 5 & 59 \\
\hline \multirow[t]{4}{*}{ Ukupno } & 4 & 8 & 34 & 17 & 21 & 4 & 9 & 93 \\
\hline & 5 & 7 & 41 & 18 & 27 & 9 & 6 & 108 \\
\hline & 6 & 18 & 41 & 17 & 25 & 8 & 9 & 118 \\
\hline & svi & 33 & 116 & 52 & 73 & 21 & 24 & $319^{1}$ \\
\hline
\end{tabular}

Odgovori povezani sa saobraćajem ponekad su u vezi sa odgovorima koji se odnose na pravac kretanja (na primer, "kod semafora skrenem levo"; "preko mosta samo pravo, pa skrenem levo" i sl). Odgovori o pravcu kretanja (zabeležili smo ih 21, što je 6,6\%) češće su se javljali kod dece od 5 i 6 godina nego kod četvorogodišnjaka, što bi moglo biti povezano sa razvojem dečjeg shvatanja prostora i orijentacije u prostoru (Pijaže i dr). Takođe, odgovori pravca kretanja kombinovani su sa odgovorima građevina (na primer, "skrenem levo kod trafike"; "idem pravo do prodavnice, pa skrenem kod igrališta" i sl).

U dečjim opisima puta od kuće do vrtića relativno se često pominju zelene površine (52 odgovora, 16,3\%), i to najrazličitijih vrsta i veličina, od parka, igrališta, do trave, drveća, žbuna i cveća. Ovi odgovori gotovo su ravnomerno prisutni kod dece oba pola i sva tri uzrasta, zbog čega se smatra

\footnotetext{
${ }^{1}$ Broj odgovora na ovo pitanje je veći od ukupnog broja dece u uzorku, jer su deca u jednom odgovoru navodila više orijentira.
} 
da je priroda nešto što privlači pažnju svih predškolaca. Ponekad deca ove odgovore kombinuju sa životinjama ("vidim ptice, mačku na drvetu" i sl).

Drugi ljudi takođe su ono što deca opažaju (33 odgovora, 10,34\%), s tim što su ovi odgovori češće dobijani od šestogodišnjaka nego od mlađe dece i češće od dečaka nego od devojčica. Ove odgovore deca ponekad kombinuju sa saobraćajnicama (na primer, "vidim ljude koji čekaju autobus") ili sa zelenim površinama ("vidim čiku koji šeta kera u parku"), kao i sa građevinama ("prođem pored zgrade gde žive baba i deda", "gde živi drug/arica" i sl).

U kategoriji odgovora „nešto drugo“ (24 odgovora, 7,52\%) gotovo polovina zabeleženih odgovora se odnosi na konfiguraciju tla, na primer: breg, kamenje, rupa, zemlja. Dečja iskustva sa okolinom sigurno se razlikuju od iskustva odraslih zbog već pomenute razlike u veličini. Ukoliko je dete manje, njegov pogled je bliži zemlji i to je sigurno jedan od razloga zašto su se pomenuti orijentiri našli u odgovorima dece. Pored toga, kako je detetovo iskustvo u opažanju relativno ograničeno i u isto vreme oslobođeno društvene svesti/ razmišljanja, ono je pod direktnijim uticajem neposrednog čulnog iskustva nego odrasli. Tako su se u njihovim odgovorima našli i odgovori kao, na primer: "čujem petlove da pevaju"; "čujem ptice"; "prođem pored slike krokodila"; "vidim smeće". Dobijena su i dva odgovora „ne vidim ništa“ $\mathrm{i}$ to od dece koju roditelji dovoze u vrtić kolima. Jedno dete je reklo i da prespava put od kuće do vrtića pa zato ništa ne vidi. U okviru ove kategorije nije zapažena značajna razlika u odgovorima u odnosu na pol i uzrast, zbog čega se veruje da je neposredno iskustvo koje dete stiče presudniji faktor za njegovo razumevanje prostora i snalaženje u prostoru. Kada se odgovori na ovo pitanje uporede sa odgovorima na prethodna dva, može se primetiti da stalnost i predvidivost osobe sa kojom dolaze utiče na bolje opažanje puta kojim se dete kreće. Takođe, način na koji dolaze utiče na opažanje, pri čemu deca koja dolaze sa bakom i/ili dekom peške i/ili biciklom daju najopširnije opise onoga što vide i kuda se kreću. 
Tabela 4. Odgovori na pitanje 4. Kako znaš kad si stigao/la?

\begin{tabular}{|c|c|c|c|c|c|c|c|c|}
\hline Kategorije: & & $\begin{array}{l}\text { Neodređeni } \\
\text { odgovori }\end{array}$ & $\begin{array}{l}\text { "Mama } \\
\text { kaže" }\end{array}$ & $\begin{array}{l}\text { Izgled } \\
\text { vrtića }\end{array}$ & $\begin{array}{l}\text { Poznate } \\
\text { osobe }\end{array}$ & $\begin{array}{l}\text { Kombinacija } \\
\text { prethodnih } \\
\text { kategorija }\end{array}$ & $\begin{array}{l}\text { Nešto } \\
\text { drugo }\end{array}$ & Ukupno \\
\hline Pol & Uzrast & & & & & & & \\
\hline \multirow{3}{*}{ Devojčice } & 4 & 2 & 4 & 11 & 3 & 0 & 7 & 27 \\
\hline & 5 & 6 & 1 & 16 & 0 & 1 & 2 & 26 \\
\hline & 6 & 2 & 0 & 15 & 2 & 3 & 3 & 25 \\
\hline \multirow[t]{3}{*}{ Dečaci } & 4 & 6 & 3 & 10 & 4 & 2 & 1 & 26 \\
\hline & 5 & 2 & 3 & 12 & 3 & 2 & 4 & 26 \\
\hline & 6 & 3 & 3 & 14 & 1 & 2 & 3 & 26 \\
\hline \multirow[t]{4}{*}{ Ukupno } & 4 & 8 & 7 & 21 & 7 & 2 & 8 & 53 \\
\hline & 5 & 8 & 4 & 28 & 3 & 3 & 6 & 52 \\
\hline & 6 & 5 & 3 & 29 & 3 & 5 & 6 & 51 \\
\hline & Svi & 21 & 14 & 78 & 13 & 10 & 20 & 156 \\
\hline
\end{tabular}

Oko polovina dece uzorka zna da su stigla u vrtić kad ugledaju zgradu vrtića (78 odgovora, 50\%). Neki to jednostavno kažu „Znam kako izgleda vrtić.“, dok drugi opisuju boju fasade, ogradu, igralište, goliće, cveće oko vrtića i dr. Ovaj odgovor je nešto češći kod dece od 5 i 6 godina nego kod četvorogodišnjaka, a između dečaka i devojčica nema značajne razlike. Drugi odgovor po učestalosti su neodređeni odgovori dece (21 odgovor, 13,5\%), kao na primer: „Eto, tako.“, „Zato što sam stigao.“, „Pa, znam!“. Ovi odgovori su češći kod dece od 4 i 5 godina nego kod šestogodišnjaka, štp se može povezati sa sazrevanjem i razvojem opažanja i shvatanja prostora, ali i sa razvojem govora. Deca od 6 godina se ne samo bolje orijentišu u prostoru, već najčešće imaju i razvijeniji govor, te umeju bolje verbalno da se izraze.

Značajan broj odgovora (20 odgovora, 12,8\%) uvršćen je u kategoriju „nešto drugo“, gde su najbrojniji odgovori dece koji se odnose na druge građevine koje se nalaze u blizini vrtića (restoran, radnja i ponovo škola), saobraćajnice (na primer, "znam put do vrtića"; "podseti me pešački prelaz" i sl) i pravac kretanja ("skrenem desno i vidim vrtić"). Ovde su svrstani i odgovori koji se odnose na procenu udaljenosti ("blizu je, pa zato znam") i vreme ("bude 8!"). Izdvojio se odgovor jedne devojčice od 6 godina: „Piše ime vrtića...“, koji kao i odgovori u kojima deca navode školu kao orijentir pokazuje preokupaciju deteta polaskom u školu. Karakterističan je i odgovor 
devojčice od 4 godine: „Zato što sam pametna“ (zato zna da je stigla), koji nedvosmisleno ukazuje na visok stepen samopouzdanja.

Nasuprot poslednje navedenom odgovoru su odgovori dece koji su svrstani u kategoriju „mama kaže“ (14 dece, 9\% uzorka), gde su pored toga da mama kaže, dobijeni i odgovori: "tata me probudi", "mama me spusti sa bicikla" i sl. U svima njima dominira odrasli autoritet kao merilo/pokazatelj, a ne neposredno iskustvo deteta, kao, na primer, u odgovorima u kojima deca navode da vide vrtić. Odgovori „mama kaže“ najčešće su dobijani od najmlađe dece, a sa rastom uzrasta njihov broj se smanjuje. Nije uočljiva značajna razlika između devojčica i dečaka.

Deca još navode poznate osobe kao orijentire (13 odgovora, 8,3\%) kao, na primer, drugare, vaspitačice, bebe. U jednom broju odgovora deca kombinuju prethodno pomenute odgovore (10 odgovora, 6,4\%), najčešće vrtić i poznate osobe (drugare i vaspitače) ili vrtić i drveće, cveće i sl.

U odgovorima dece mogu se uočiti uzrasne i individualne razlike, kao i razlike vezane za različito iskustvo koje deca imaju u interakciji sa svojom okolinom. Kada opisuju svoj put od kuće do vrtića, navode neke uobičajene orijentire za gradsku sredinu (građevine, saobraćajnice, zelene površine), ali i neke orijentire koje odrasli ne primećuju (ograde, smeće ili cvrkut ptica!). U njihovom opažanju okoline bitna je i motivacija, kao u primeru navođenja škole ili benzinske pumpe.

\section{Analiza dečjih crteža}

U analizi crteža mape puta od kuće do vrtića krenulo se od toga da li je dete crtalo mapu ili ilustraciju svog puta. Za procenu da li je nacrtana mapa ili ilustracija osnovni kriterijum je bio ugao iz kojeg dete predstavlja prostor. Mapom je smatran crtež na kojem dete prikazuje pogled odozgo, odnosno pravi tlocrt prostora, te tako prikazuje svoju predstavu organizacije i povezivanja pojedinih prostora i elemenata predstavljenih u njemu. Takođe, značajno je da li i kako dete predstavalja svoje kretanje u prostoru, putanju. Posebno je analizirano da li je ono što je nacrtano povezano sa verbalnim iskazom i prisustvo detalja na crtežima. 
Preko polovina dece iz uzorka (56\%) nacrtalo je mapu svog puta od kuće do vrtića, s tim što se taj procenat progresivno povećavao sa povećanjem uzrasta dece (25\% četvorogodišnjaka, oko $62 \%$ petogodišnjaka i približno $68 \%$ šestogodišnjaka). Uzrasne razlike su očekivane i veruje se da su povezane sa sazrevanjem saznajnih i grafičkih sposobnosti dece. U uzorku se nije pojavila značajna razlika u pogledu pola dece. Crtanje mape smatra se važnim podatkom, jer se u literaturi (Djačenko i Lavrentjev, 1988) ističe značaj povezanosti orijentacije u prostoru i sposobnosti korišćenja mapa. Sa jedne strane, relativno veliki procenat dece koja crtaju mape (naročito petogodišnjaka i šestogodišnjaka) ukazuje da se relativno veliki procenat dece iz uzorka dobro snalazi u prostoru. Sa druge strane, isticanje ove povezanosti ukazuje i na moguće postupke kako da se kod dece podrži dalji razvoj ove sposobnosti, upravo dajući deci predloge da crtaju mape raznih prostora, njima važnih i zanimljivih.

Putanja koju dete prolazi od kuće do vrtića prisutna je na gotovo svim dečjim radovima. Čak i kada ctaju ilustraciju svog puta (ne mape), put je vrlo često u centru crteža, ili je jasno uočljiv na crtežu. Deca mlađeg uzrasta najčešće put / putanju crtaju kombinujući pune i isprekidane linije, ponekad i tačke, što jasno asocira na kretanje (Belamarić, 1986:31). Ponekad kretanje predstavljaju sa više punih linija koje povlače približno paralelno između dve nacrtane kuće, veće i manje, koje jasno asociraju na vrtić i kuću. Starija deca (pet i šest godina) češće koriste isprekidane linije da bi označila putanju, na mapama se kod starije dece mogu videti čitave raskrsnice sa semaforima, pešačkim prelazima, saobraćajnim znacima, automobilima, parkingom i sl. Kod manjeg broja starije dece prisutne su i strelice koje označavaju pravac kretanja. Strelice su važan elemenat mape, jer pokazuju smer / pravac kretanja, dok kada nema strelica - vidi se samo putanja. Strelica je simbol i njeno korišćenje ukazuje na detetovu sposobnost upotrebe simbola. Pojedina deca koristila su i druge simbole, kao na primer znak "P" pored parkinga. Šestogodišnjaci su ponekad pisali i natpise na zgradama, kao na primer "Vrtić" ili "Idea", a ponekad i svoje ime. Očigledno je da se s uzrastom dece proširuje i upotpunjuje njihovo shvatanje prostora a takođe i sposobnost njegovog grafičkog predstavljanja. 
Ovo još više dolazi do izražaja kada se analiziraju detalji koji su prisutni na crtežima. Kod mlađe dece detalji su u proseku ređe prisutni, manji ih je broj i ponekad su očigledno šablonski rađeni (sunce, oblak, srce i sl). Starija deca crtaju veći broj detalja koji su specifičniji, u funkciji boljeg prikaza samog puta, na primer, fudbalski teren sa golićima, kuća sa psom, zgrada sa karakterističnom fasadom i sl.

Većina crteža dece povezana je sa njihovim verbalnim iskazima. U slučajevima kada je uočena neusaglašenost, najčešće je na crtežima nedostajalo nešto od onoga što su deca ispričala tokom razgovora, odnosno verbalni iskaz je bio detaljniji i precizniji nego crtež. Događalo se i obrnuto, da pojedina deca koja nisu verbalno precizno opisala pravac kretanja i odnose među objektima, na crtežima su ih jasnije prikazala. U razgovoru sa vaspitačima, saznalo se da su ponekad i oni bili iznenađeni kad su shvatili da deca daju tačnu i preciznu sliku svog puta od kuće do vrtića. Jedna vaspitačica je rekla: "Oduševili su me koliko su zapamtili neke detalje, kao na primer, zgrada sa crvenim krovom, parking ispred vrtića, gde je truckanje..." Slične su bile i reakcije vaspitača na crteže dece. Jedna vaspitačica je oduševljeno ispričala: "Na crtežima tačno mogu da vidim muzičku školu, bioskop, glavnu ulicu kroz koju prolaze, autobuse, SPENS, pekare..."

\section{ZAKLJUČNA RAZMATRANJA}

Postoje brojni dokazi u teoriji (Pijaže, Vigotski i drugi) da je opažanje, shvatanje i predstavljanje prostora kod dece predškolskog uzrasta veoma važno za njihov celokupan razvoj, kao i za razvoj brojnih specifičnih veština. Najopštije gledano, prostorni razvoj se smatra značajnim sa teorijske, praktične i evolucijske tačke gledišta (Newcombe et al. 2013). Istraživanja su pokazala (Caspe et al. 2015; Djačenko i Lavrentjeva, 1988; Klemenović, 2014, Newcombe et al. 2013) da, pored toga što deca od 4 do 6 godina najčešće dobro opažaju i pravilno imenuju prostorne odnose i pravac kretanja u prostoru, za razvoj shvatanja prostora je dobro, pored direktnog podučavanja, koristiti različite posredne načine podsticanja u svakodnevnim životnim situacijama koje su za dete važne i razumljive. Jedna od takvih 
situacija je i dolazak deteta $\mathrm{u}$ vrtić, što se svakodnevno događa, a - u zavisnosti od toga kako je organizovan - obezbeđuje detetu različita iskustva.

Iz rezultata prikazanog istraživanja, može se zaključiti da deca obuhvaćena uzorkom relativno dobro opažaju, razumeju i predstavljaju prostor u kojem se svakodnevno kreću. Dobijeni odgovori pokazuju da većina ispitane dece ima stalnost i predvidivost osoba sa kojima dolazi $u$ vrtić, kao i načina na koji dolazi. S tim je povezan opis puta od kuće do vrtića, gde se primećuje da stalnost i predvidivost osoba sa kojima dete dolazi u vrtić utiče na njihovo bolje opažanje puta kojim se kreću. Deca koja dolaze peške i biciklom u vrtić daju opširnije opise puta, sa više detalja, nego deca koja dolaze autom i javnim prevozom. Najčešći orijentiri u prostoru koje deca navode su građevine, zatim saobraćajnice, zelene površine i osobe koje sreću. Pravac kretanja češće opisuju starija deca, što je u vezi sa razvojem prostornog orijentisanja, ali isto tako i sa razvojem govora, odnosno poznavanjem pojmova povezanih sa prostorom.

Analiza dečjih crteža je pokazala da relativno veliki procenat dece, naročito petogodišnjaka i šestogodišnjaka, crta mape puta, dok deca mlađeg uzrasta češće ilustruju put od kuće do vrtića. Korišćenje mape smatra se jednim od načina simboličkog predstavljanja prostora, pored korišćenja reči kojima se opisuje prostorna orijentacija. Putanja je prisutna na gotovo svim likovnim radovima dece, $s$ tim što je kod dece starijih uzrasta češće prisutno i simboličko predstavljanje pravca kretanja. Detalji su češće prisutni na crtežima starije dece, a takođe su smisaono povezani i u funkciji boljeg predstavljanja prostora, dok su kod mlađe dece ne samo ređe prisutni, već i kada ih crtaju oni češće imaju dekorativni karakter. Većina crteža je povezana sa verbalnim iskazima dece. Kada je uočen nesklad, češće je verbalni iskaz bio detaljniji i precizniji od crteža, što znači da je kod pojedine dece razvoj govora na višem nivou nego razvoj grafičkih sposobnosti.

Jedna od vrednosti ovog istraživanja je to što su povezane dve komponetne prostorno simboličkog sistema, prostorni jezik i mape. Jedan od pravac daljeg istraživanja mogao bi biti uključivanje i treće komponente gestova. To tim pre što su neverbalni oblici komunikacije od velike važnosti za predškolsu decu, samim tim što još nisu u potpunosti ovladala govorom kao simboličkim sistemom. Pored uobičajenih ograničenja koja imaju 
istraživanja rađena na prigodnom uzorku, autori smatraju da su dobijeni rezultati vredni jer ukazuju na moguće pravce daljeg istraživanja. Istraživanje na reprezentativnom uzroku dalo bi sigurno potpuniju sliku predmeta istraživanja, ali bi dragoceno bilo i analizirati veći broj različitih životno značajnih situacija. Time bi se osvetlile i brojne druge prilike i situacije koje doprinose razvoju opažanja, shvatanja i predstavljanja prostora kod dece.

Rezultati istraživanja pokazuju da praktična životna aktivnost, dolazak deteta u vrtić, nije u dovoljnoj meri iskorišćena za razvoj pojmova o prostoru kod dece. Za podsticanje dečjeg opažanja, shvatanja i simboličkog predstavljanja prostora potrebno je iskoristiti različite situacije i aktivnosti zanimljive deci, kao, na primer, izlazak napolje, šetnje i dr. Vaspitači predškolske dece treba svakodnevno da koriste reči za prostornu orijentaciju (pored, iza, ispred, gore, dole, levo, desno i dr), zatim, da podstiču decu da češće crtaju mape različitih prostora (zatvorenih i otvorenih) i da se više služe različitim simbolima. Takođe, korisne su igre tipa tangrama, pazl, igre sa ogledalima, jer one podstiču razvoj prostornih veština.

Pored toga, vaspitači mogu da sugerišu roditeljima dece da $u$ svakodnevnom govoru koriste reči za prostornu orijentaciju, kao i različite druge aktivnosti u vezi sa prostornim ponašanjem i prostornim simboloma. $\mathrm{Na}$ primer, može se predložiti da roditelji zajedno sa decom pišu priču o omiljenim aktivnostima a deca da je ilustruju. Zatim, da se deci daju fotografije različitih prostora (na primer, razglednice, turistički prospekti i sl) i da se deca podstiču da ih objasne. Na taj način će se obogatiti dečje iskustvo o prostoru i podstaći simboličko predstavljanje prostora. 


\title{
OBSERVATION, UNDERSTANDING AND REPRESENTATION OF SPACE IN PRESCHOOL CHILDREN
}

\begin{abstract}
Children orientation in space is significant for their overall development, as well as for the development of specific skills, which are important both for coping in everyday life and for success in particular school subjects (especially for reading, writing, arithmetic, art and physical education). Arrival of children to a kindergarten as an everyday life situation can provide valuable experiences for the development of orientation in space. The aim of this study is to determine how children perceive, understand and graphically represent the spacein which they move on daily basis. The research sample consisted of 156 subjects (children), 52 of them were four years old, and 52 of them were six years old, with equal proportion of girls and boys. All the children attended kindergartens in Novi Sad. The method of interviewing and drawing a roadmap from home to the kindergarten was applied in the research. The results of the research obtained by the analysis of responses to the questions and the analysis of the children's drawings indicate that the children involved in the research relatively well perceive, understand and represent the space. However, this situation is not sufficiently used for improvement of children's understanding of the direction of movement and the use of symbols in space representation. We can conclude that adults should pay more attention to children's direct experience, to discussions with children about their perception of space and spatial relations. Also we would like to propose that it would be a great benefit if adults would more often encourage children to draw maps and use different symbols.
\end{abstract}

KEY WORDS: children, space, perception, understanding, space representation. 


\section{REFERENCE}

Belamarić, D. (1986). Dijete i oblik. Zagreb: Školska knjiga.

Caspe, M., Lopez M. E. \& Chattrabhuti, C. (2015). Four Important Things to Know About the Transition to School: Harvard Family Research Project.

Dauksas, L., \& White, J. (2014). Discovering Shapes and Space in Preschool. Teaching Young Children, 7(4), 22-25.

Djačenko, O.M. i Lavrentjeva T. V. (1988). Psihički razvoj predškolske dece. Beograd: ZUNS.

Jerković, I. i Zotović, M. (2010). Razvojna psihologija. Novi Sad: Futura publikacije.

Klemenović, J. (2014). Spemnost za školu u inkluzivnom kontekstu. Novi Sad: Filozofski fakultet.

Newcombe, S. N., Uttal, H. D. \& Sauter, M. (2013). Spatial Development.

In: P. D. Zelazo (Ed.), The Oxford Handbook of Developmental Psychology (pp. 1-66). Oxford: Oxford University Press.

Linč, K. (1974). Slika jednog grada. Beograd: Građevinska knjiga.

Medouz, S. i Kešdan, A. (2000). Kako pomoći deci da uče. Beograd: ZUNS.

Pijaže, Ž. i Inhelder, B. ( 1986). Intelektualni razvoj deteta. Beograd: ZUNS.

Tarner, Dž. (1979). Saznajni razvoj. Beograd: Nolit. 